\title{
Safety, health, and environmental assessment of bioethanol production from sugarcane, corn, and corn stover
}

\section{Journal Article}

Author(s):

Banimostafa, Alireza; Nguyen, Thuy Thi Hong; Kikuchi, Yasunori; Papadokonstantakis, Stavros; Sugiyama, Hirokazu; Hirao, Masahiko; Hungerbühler, Konrad

Publication date:

2012

Permanent link:

https://doi.org/10.3929/ethz-b-000060826

Rights / license:

In Copyright - Non-Commercial Use Permitted

Originally published in:

Green Processing and Synthesis 1(5), https://doi.org/10.1515/gps-2012-0042 
Alireza Banimostafa, Thuy Thi Hong Nguyen, Yasunori Kikuchi, Stavros Papadokonstantakis*, Hirokazu Sugiyama, Masahiko Hirao and Konrad Hungerbühler

\section{Safety, health, and environmental assessment of bioethanol production from sugarcane, corn, and corn stover}

\begin{abstract}
Biofuels as renewable resources are one of the options to meet the challenges of fossil fuel resource depletion and atmospheric pollution. Several studies have focused on the technical, economic, and environmental footprint of biofuels, particularly bioethanol production. However, there has been little effort to incorporate the environmental, health, and safety (EHS) hazards in an inclusive sustainability assessment of bioethanol production alternatives. This study focuses on these sustainability aspects for bioethanol production by employing the EHS and the inherent safety index (ISI) methods. The multicriteria assessment also includes the cumulative energy demand as a widely used lifecycle impact assessment indicator. Sugarcane, corn, and corn stover are considered as biomass resources, and the typical process conditions are used for the base case evaluation. Sensitivity analysis is used to investigate the impact of process conditions, composition of feed, and method settings on the final outcome. The results indicate that both the ISI and the EHS methods present similar overall rankings with sugarcane-derived and corn stover-derived processes as the most and the least hazardous, respectively. However, dissimilarities occur in the evaluation of the process sections, highlighting different hazardous aspects. Finally, including the lifecycle impact assessment in a bicriteria assessment indicates the sugarcane-derived process as clearly superior followed by the corn-derived and the corn stover-derived processes.
\end{abstract}

Keywords: biofuels; hazard assessment methods; inherent safety index; lignocellulosic biomass; sustainable production processes.

\footnotetext{
*Corresponding author: Stavros Papadokonstantakis, Institute for Chemical- and Bioengineering, Safety and Environmental Technology Group, Swiss Federal Institute of Technology Zurich (ETHZ), Wolfgang-Pauli-Strasse 10, 8093 Zurich, Switzerland, e-mail: stavros.papadokonstantakis@chem.ethz.ch

Alireza Banimostafa: Institute for Chemical- and Bioengineering, Safety and Environmental Technology Group, Swiss Federal Institute of Technology Zurich (ETHZ), Wolfgang-Pauli-Strasse 10, 8093 Zurich, Switzerland
}

Thuy Thi Hong Nguyen: Department of Chemical System Engineering, The University of Tokyo, 7-3-1 Hongo, Bunkyo-ku, Tokyo 113-8656, Japan Yasunori Kikuchi: Department of Chemical System Engineering, The University of Tokyo, 7-3-1 Hongo, Bunkyo-ku, Tokyo 113-8656, Japan

Hirokazu Sugiyama: Institute for Chemical- and Bioengineering, Safety and Environmental Technology Group, Swiss Federal Institute of Technology Zurich (ETHZ), Wolfgang-Pauli-Strasse 10, 8093 Zurich, Switzerland

Masahiko Hirao: Department of Chemical System Engineering, The University of Tokyo, 7-3-1 Hongo, Bunkyo-ku, Tokyo 113-8656, Japan

Konrad Hungerbühler: Institute for Chemical- and Bioengineering, Safety and Environmental Technology Group, Swiss Federal Institute of Technology Zurich (ETHZ), Wolfgang-Pauli-Strasse 10, 8093 Zurich, Switzerland

\section{Introduction}

The concept of substituting fossil resources with biomass for the production of ethanol has received significant attention to decrease greenhouse gases and switch to renewable energy sources. Bioethanol can be produced from different kinds of biomass, which can be classified into three main groups: sucrose-containing materials, starchy materials, and lignocellulosic biomass [1]. Various aspects of bioethanol production and environmental impacts have been discussed in previous studies. The process design trends of energy production from different kinds of bioresources have been reviewed [2, 3] and technoeconomic analysis has been performed for the state-of-the-art and future pretreatment and conversion technologies [4], including the international transport for bioenergy supply chains [5]. The environmental impact, mainly expressed as greenhouse gases emissions, has also been evaluated for bioethanol production from various feedstock, including corn in the USA [6-9], sugarcane in Brazil [10,11] and corn stover [12, 13]. Additionally, the issues of biomass availability [14] and water and land use $[15,16]$ have also been studied. 
When designing a process including a new technology, various aspects of process systems should be carefully checked. Besides resource consumption and availability discussed in the previous studies on biomass, the local hazard issues must be carefully analyzed to implement diverse biomass technologies [17]. Especially for energy sources, it has been recognized that process safety should be one of the most important viewpoints [18], that is, technologies with high safety risk should be reconsidered even if they can significantly reduce the environmental impacts. Because bioethanol production has been considered as a technology for producing energy or materials sustainably, the safety aspects of the production processes must be clarified and carefully checked before a large-scale implementation. However, the studies about the process safety analysis of bioethanol production are lacking, although similar studies have been conducted for biodiesel [19], and there are some reports on the safety of the transportation and handling of bioethanol [20] and the production of bioderived products from bioethanol [21]. In general, the different kinds of biomass used for bioethanol production require different technologies of pretreatment and fermentation, resulting in diverse process structures and operating conditions, which can directly influence the safety performance.

In this article, we aim to contribute to the sustainability analysis of bioethanol production processes via the application of systematic safety, environmental and health hazard assessment methods. Bioethanol production processes derived from three main kinds of biomass were studied, that is, sugarcane, corn, and corn stover containing sucrose, starch, and cellulose, respectively. The bioethanol production from these resources has been well studied and documented in literature with respect to mass and energy balances and available technologies, providing the necessary information for the hazard assessment methods. Two hazard assessment methods were applied: the inherent safety index (ISI) [22] method and the environmental, health, and safety (EHS) method [23]. These methods have also been recently integrated into process retrofitting [24] and conceptual design frameworks [25]. Although both methods consider substance properties and process conditions and can provide categorical and aggregated results to a single metric, they also quantify different aspects of process hazards. Based on these different hazard assessment methods, the risk factors of bioethanol production technologies can be comprehensively revealed. The present study also demonstrates how these or similar hazard-oriented metrics could be combined with other design metrics to enhance multicriteria decision-making. In this study, cumulative energy demand (CED) is adopted as a design metric for environmental impacts, because it has strong correlation with other metrics in lifecycle impact assessment (LCIA), such as global warming potential or EcoIndicator 99, and can be applied to estimate the environmental burden [26-28].

\section{Materials and methods}

\subsection{Alternative processes for producing bioethanol}

The simplified flowsheets of bioethanol production processes from three types of feedstock are shown in Figure $1 \mathrm{~A}-\mathrm{C}$ (see also section 1, Table $\mathrm{S} 1$ in the Supporting Information for feedstock composition). Each process is divided into three main stages: pretreatment of input feedstock, fermentation, and purification of ethanol. All considered processes are described briefly below, and the operating conditions of the main process units are summarized in Table 1 (see also section 2, Tables S2-S10 in the Supporting Information for the considered reactions and the derived mass balances). Different methods and operating conditions have been recommended for the optimal performance of the considered process stages; however, only the widely studied ones are applied and evaluated in the present study. It should be noted that the agricultural steps for the production of the biomass feedstock as well as the waste treatment and byproduct recovery stages are not considered in this study for the hazard assessment of the bioethanol processes, and for this reason, the respective flowsheets are not presented in Figure 1A-C. This selection for the system boundaries corresponds to the common practice of analyzing the hazards "locally", that is, for a certain plant facility, which, in this case, is defined as the bioethanol production section. In this context, the waste management of the process effluents is assumed to be done centrally in a dedicated plant facility for waste treatment together with effluents from other processes. Moreover, the bioethanol process does not implicate any special type of waste treatment. The byproduct recovery stages as well as the other mass and heat integration potential of the bioethanol processes are not included in the respective flowsheets due to lack of explicit information (i.e., process conditions and efficiencies) required for the mass balances and the hazard assessment. However, it should be noted that, for the LCIA included in the multicriteria process assessment of this 

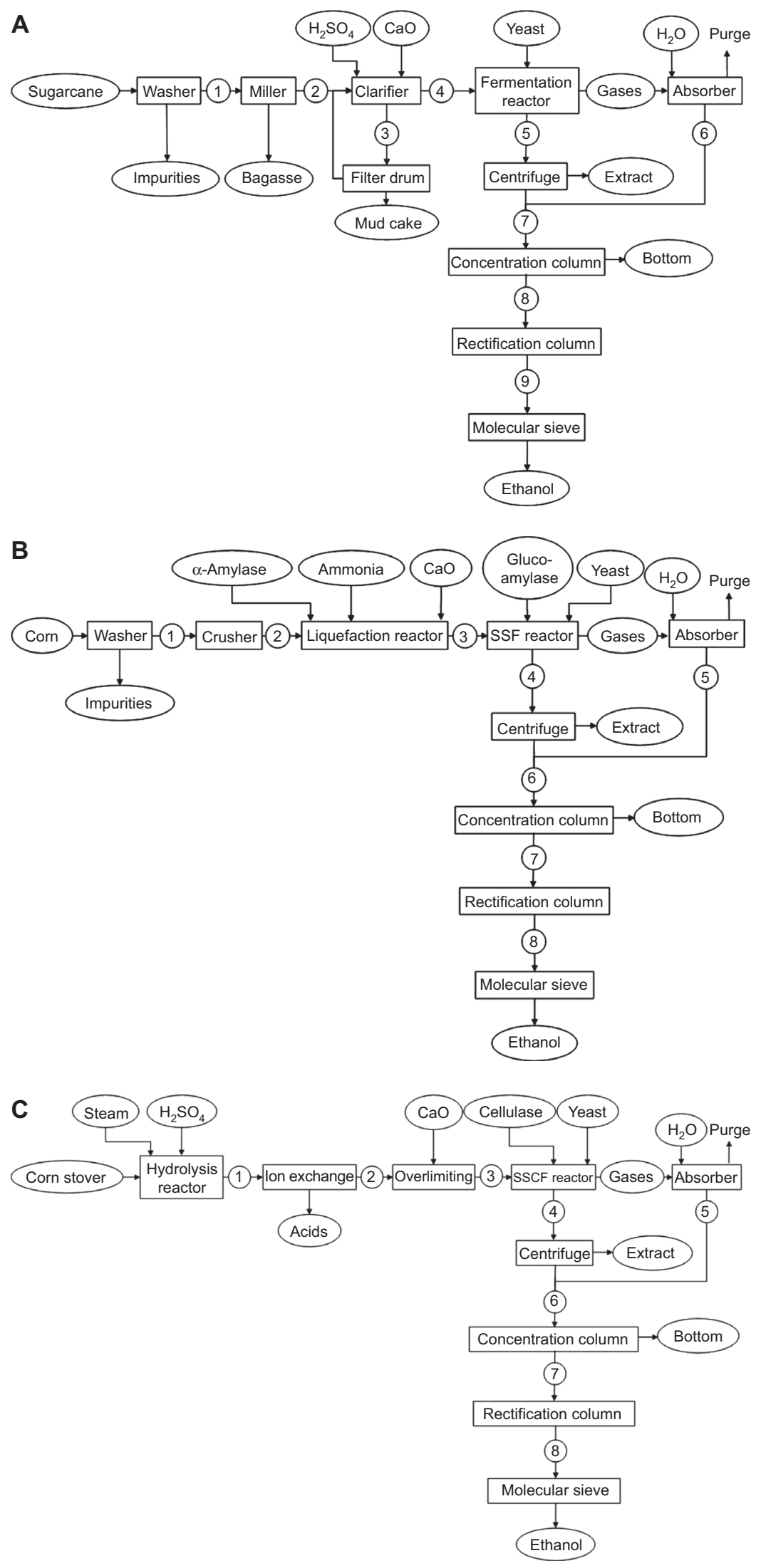

Figure 1 Simplified flowsheets of bioethanol production processes considering the main unit operations and process streams. (A) Sugarcane-derived process [10, 14]. (B) Corn-derived process [1, 14]. (C) Corn stover-derived process [1, 2]. 


\begin{tabular}{|c|c|c|c|}
\hline & $\begin{array}{l}\text { Sugarcane-derived } \\
\text { process }\end{array}$ & Corn-derived process & $\begin{array}{l}\text { Corn stover-derived } \\
\text { process }\end{array}$ \\
\hline Weight percent of key component & Sucrose: $14 \%$ & Starch: $60.6 \%$ & Cellulose: $40.9 \%$ \\
\hline \multicolumn{4}{|l|}{ Pretreatment } \\
\hline Main method & Clarifier $[29,30]$ & Liquefaction $[29,31-33]$ & $\begin{array}{l}\text { Steam explosion+acid } \\
\text { hydrolysis }[31,34]\end{array}$ \\
\hline Conditions & $\begin{array}{l}\mathrm{T}=65^{\circ} \mathrm{C}[29,30] ; \\
\mathrm{pH}=7.8[29,30]\end{array}$ & $\begin{array}{l}\mathrm{T}=80-88^{\circ} \mathrm{C}[29,31-33] ; \\
\mathrm{pH}=6.5[29,31]\end{array}$ & $\begin{array}{l}\mathrm{T}=180-200^{\circ} \mathrm{C}[31,34] ; \\
\mathrm{p}=12 \mathrm{~atm}[31,34]\end{array}$ \\
\hline \multicolumn{4}{|l|}{ Fermentation } \\
\hline Enzyme and yeast & $\begin{array}{l}\text { Saccharomyces } \\
\text { cerevisiae [29] }\end{array}$ & $\begin{array}{l}\text { Glucoamylase and } \\
\text { S. cerevisiae [29] }\end{array}$ & $\begin{array}{l}\text { Cellulase and Zymo- } \\
\text { monas mobilis [34] }\end{array}$ \\
\hline Temperature $\left({ }^{\circ} \mathrm{C}\right)$ & $31[29]$ & $34[31]$ & $30[34]$ \\
\hline Conversion of key component to glucose & Sucrose: $90 \%[29]$ & Starch: 99\% [29] & Cellulose: $80 \%[34]$ \\
\hline Conversion of glucose to ethanol (\%) & 92 & 92 & $92[34]$ \\
\hline Weight percent of ethanol in product stream (wt\%) & $6[29,30]$ & $9[29,31]$ & $5[31,34]$ \\
\hline \multicolumn{4}{|l|}{ Concentration column } \\
\hline Pressure $(\mathrm{kPa})$ & 101.3 & $101.3[29]$ & 101.3 \\
\hline Temperature of distillate $\left({ }^{\circ} \mathrm{C}\right)$ & 80 & 80 & 80 \\
\hline Temperature of bottom $\left({ }^{\circ} \mathrm{C}\right)$ & 100 & 100 & 100 \\
\hline Weight percent of ethanol in product stream (wt\%) & 60 & 63 & 60 \\
\hline \multicolumn{4}{|l|}{ Rectification column } \\
\hline Pressure $(\mathrm{kPa})$ & 101.3 & 101.3 & 101.3 \\
\hline Temperature of distillate $\left({ }^{\circ} \mathrm{C}\right)$ & 78 & 78 & 78 \\
\hline Temperature of bottom $\left({ }^{\circ} \mathrm{C}\right)$ & 98 & 98 & 98 \\
\hline Weight percent of ethanol in product stream (wt\%) & 95 & 95 & 95 \\
\hline
\end{tabular}

Table 1 Conditions of the main process units included in bioethanol production processes.

The conversion of glucose to ethanol in the corn stover-derived process was obtained by Wooley et al. [34] and is assumed to be the same in all processes. The pressure condition of the concentration and the rectification column was obtained by Quintero et al. [29] and is assumed to be the same in all processes. The temperatures of distillate and bottom streams and the weight percent of ethanol in the product stream of the concentration and the rectification columns are obtained by simulation under the considered conditions.

study, aggregated information is available, including all relevant cradle-to-gate stages.

\subsubsection{Sugarcane-derived process}

As depicted in Figure 1A, sugarcane is washed with water for the removal of ash and organic matter. After milling, sugarcane juice is extracted (stream 2) and fed to the clarification process, where, with the aid of diluted acid and limes, all suspended matter and soluble impurities are precipitated and then removed through the filter drum. The clarified juice (stream 4) is fed to the fermentation reactor supplied with the yeast. The liquid product of the fermentation reaction (stream 5) contains $6 \%$ by weight ethanol and undergoes a centrifugation process to separate the yeast. The fermentation gaseous output from the reactor is fed to an absorber, where vaporized ethanol is recovered (stream 6). The recovered ethanol from the gas phase and the centrifuged liquid product of the fermentation reaction are led to the dehydration stage (stream 7), where ethanol is first recovered with a concentration of $60 \%$ by weight (stream 8) and finally reaches a target purity of $99.5 \%$.

\subsubsection{Corn-derived process}

As shown in Figure 1B, after the steps of washing and dry milling, starch is extracted from corn feedstock (stream 2). The cornstarch is then fed to the liquefaction reactor and the starch is gelatinized and partially hydrolyzed. The reactor product (stream 3 ) is fed to the simultaneous saccharification and fermentation (SSF) reactor, where starch is hydrolyzed to glucose and converted to ethanol by the assimilation of yeast. The SSF reactor liquid output (stream 4) consists of $9 \%$ by weight ethanol and, together with the gaseous phase ethanol recovered in the absorber, is led to the dehydration section for the production of ethanol at the desired purity.

\subsubsection{Corn stover-derived process}

In Figure 1C, the corn stover is first hydrolyzed with sulfuric acid in the hydrolysis reactor; then, under high temperature using high-pressure steam, a small amount of cellulose and most of hemicellulose portions are converted to the corresponding soluble sugars. The pro- 
duced acetic acid together with some other byproducts negatively influences the performance of subsequent fermentation reactions. Therefore, the output of the hydrolysis reactor (stream 1 ) needs to be detoxified with an ion exchange step to remove most of the acids (stream 2) and then lime is added to facilitate the formation and separation of crystals. The resulted product (stream 3) is fed to the simultaneous saccharification and cofermentation (SSCF) reactor, where the saccharification of the remaining portion of cellulose and fermentation of the resulting sugars take place using enzymes and yeast. The liquid product from the SSCF reactor (stream 4) contains $5 \%$ by weight ethanol. The rest of the process stages up to production of ethanol at the desired purity are similar to those of the sugarcane- and corn-derived processes.

\subsection{Assessment methods}

Various hazard assessment methods have been proposed and compared for process design [35-37]. In the present study, the ISI and the EHS methods were chosen to evaluate hazards for bioethanol production. These two methods have been widely applied to typical chemical production case studies, have different process data requirements, and highlight different aspects of hazard assessment. The basic concepts and settings of the EHS and the ISI methods are briefly summarized below (see also the study of Adu et al. [36] and Table A1 in the Appendix for more information about the similarities and differences between the ISI and the EHS methods).

\subsubsection{ISI method}

The original framework of the ISI method is developed by Heikkilä [22]. The ISI method consists of two main index groups: chemical ISI $\left(\mathrm{I}_{\mathrm{CI}}\right)$ and process ISI $\left(\mathrm{I}_{\mathrm{PI}}\right) \mathrm{I}_{\mathrm{CI}}$ includes the subindices of heat of main reaction, heat of potential side reaction, flammability, explosiveness, toxicity, corrosiveness, and incompatibility of chemicals. $\mathrm{I}_{\mathrm{PI}}$ includes the subindices of inventory of chemicals, process temperature and pressure, type of equipment, and structure of process. Each subindex obtains a score in a discrete scale with lower and upper bounds, the higher values indicating a more hazardous chemical substance or process feature. The method for calculating each subindex is described in detail by Heikkilä [22]. Then, $\mathrm{I}_{\mathrm{CI}}$ and $I_{P I}$ are simply calculated as the sum of these subindices and the total ISI $\left(\mathrm{I}_{\mathrm{TI}}\right)$ is the sum of $\mathrm{I}_{\mathrm{CI}}$ and $\mathrm{I}_{\mathrm{PI}}\left(\mathrm{I}_{\mathrm{TI}} \in[0,48]\right.$ if enough information is available to calculate all subindices). $\mathrm{I}_{\mathrm{TI}}$ can be calculated for each defined process section separately and summed up to an overall metric for the whole process. Apart from the method-specific scaling and aggregation schemes of the considered categories, an important feature of the method is that it only comprises a general inventory index; therefore, it is not sensitive to the mass of each specific substance as an additional hazard source to the intrinsic substance properties. This method has already been used in the assessment of biofuel production processes [19].

\subsubsection{EHS method}

In the original EHS framework of Koller et al. [23], a set of dangerous properties (mobility, fire/explosion, reaction/ decomposition, acute toxicity, irritation, chronic toxicity, air-mediated effects, water-mediated effects, solid waste, degradation, and accumulation) is defined depicting the EHS hazards. Scaling schemes are proposed, which quantify these dangerous properties for all substances involved in a process and result in substance-specific indices with values between 0 and 1 . Sugiyama et al. [25] have extended the work of Koller et al. [23] by combining the substance-specific indices with the respective process mass flows and introducing a weighting scheme for calculating first categorical scores for the EHS hazards and finally an overall EHS hazard assessment score. Both substance-specific indices and process mass flows can result from basic information about the process layout and operating conditions complemented with process modeling, wherever is necessary. This makes the EHS framework suitable for screening process alternatives from early to later phases of the basic design stage. All necessary details for the calculation of the EHS indices can be found in the original literature (some minor modifications applied here are mentioned in Table A1 in the Appendix).

\section{Results and discussion}

\subsection{ISI method}

The evaluation of the bioethanol production processes using the ISI method is presented in Figure 2. According to this analysis, the same pattern appears for all processes as far as the ranking of process sections is concerned, namely, the fermentation stage is the most hazardous fol- 


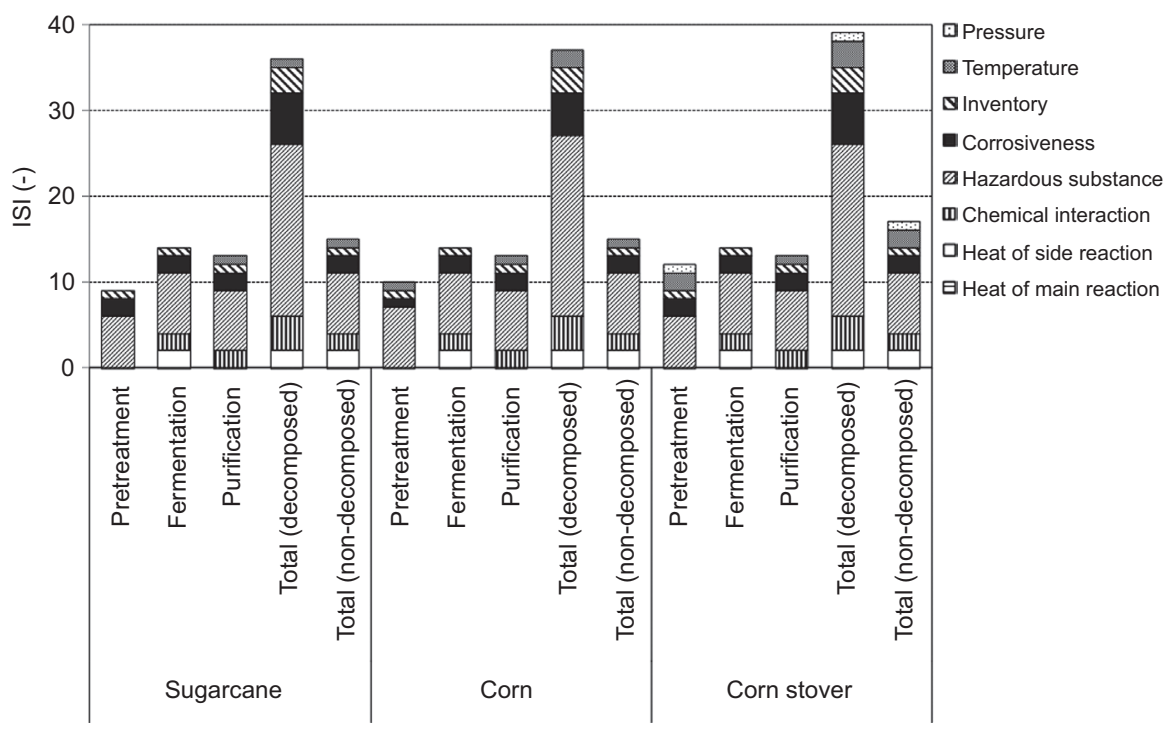

Figure 2 ISI of alternative bioethanol production processes.

Hazardous substances and severe process conditions result in higher ISI values. The subindices of the ISI method referring to process structure and equipment safety are not calculated, because they lie outside the scope of process analysis based on simplified flowsheets (i.e., ISI maximum possible value per process section is 39 for the present study). The process assessment is done in two ways: (i) by considering three different process sections separately (pretreatment, fermentation, and purification sections) resulting in the total (decomposed) endpoint score and (ii) by considering the whole process as one section resulting in the total (nondecomposed) endpoint score.

lowed by the purification and the pretreatment stages. This is mainly due to the heat release from the exothermic reactions during the fermentation (e.g., the side reaction forming acetic acid from glucose) and the reactivity of the byproducts (e.g., acetic acid, lactic acid, and succinic acid). The latter also applies for the purification section, where ethanol is purified from these byproducts.

The feedstock pretreatment of the sugarcane-derived process obtains the lowest ISI score mainly because it is performed at lower temperature compared with the cornderived and the corn stover-derived processes. Essentially, the difference of operating conditions applied in the pretreatment step is the main factor that differentiates the investigated bioethanol production processes according to the ISI method. According to this ranking, the sugarcane-derived process is the safest one followed closely by the corn-derived and the corn stover-derived processes.

Finally, it is tested whether the ranking results are sensitive to boundary conditions of the analysis, as expressed by the ranges for biomass composition, and process operating conditions reported in Table 1. It is shown that neither the variations in process operating conditions nor the feedstock composition from different parts of the world distort the ranking results of the ISI method (see also section 3, Table S11 in the Supporting Information).

However, the marginal superiority of the sugarcanederived process regarding safety aspects disappears when the whole process is taken as one section [i.e., comparing total (decomposed) and total (nondecomposed), respectively, in Figure 2]. The reason is that process decomposition highlights section-specific hazards, which are not revealed if no decomposition is performed. This indicates that the ISI method settings defined by the decision-maker can sometimes be more important than process operating parameters.

\subsection{EHS method}

The evaluation of the bioethanol production processes using the EHS method is presented in Figure 3. Again, the same patterns appear in all three processes regarding the ranking of the process sections, that is, fermentation is ranked as the least hazardous section followed by the pretreatment and the purification sections. Interestingly, this pattern is different from the one proposed by the ISI method (Figure 2). The EHS method penalizes the purification section mainly due to the higher values of persistency, arising from the existence of $\mathrm{CO}_{2}$ in the purge of the absorber. The persistency category refers to the environmental effects not captured by the ISI method; therefore, the differentiation of the EHS method results is justified from this point of view. It should also be noted that some of the considered categories in the EHS method (e.g., water- and air-mediated effects), which are not included in the safety-oriented ISI 


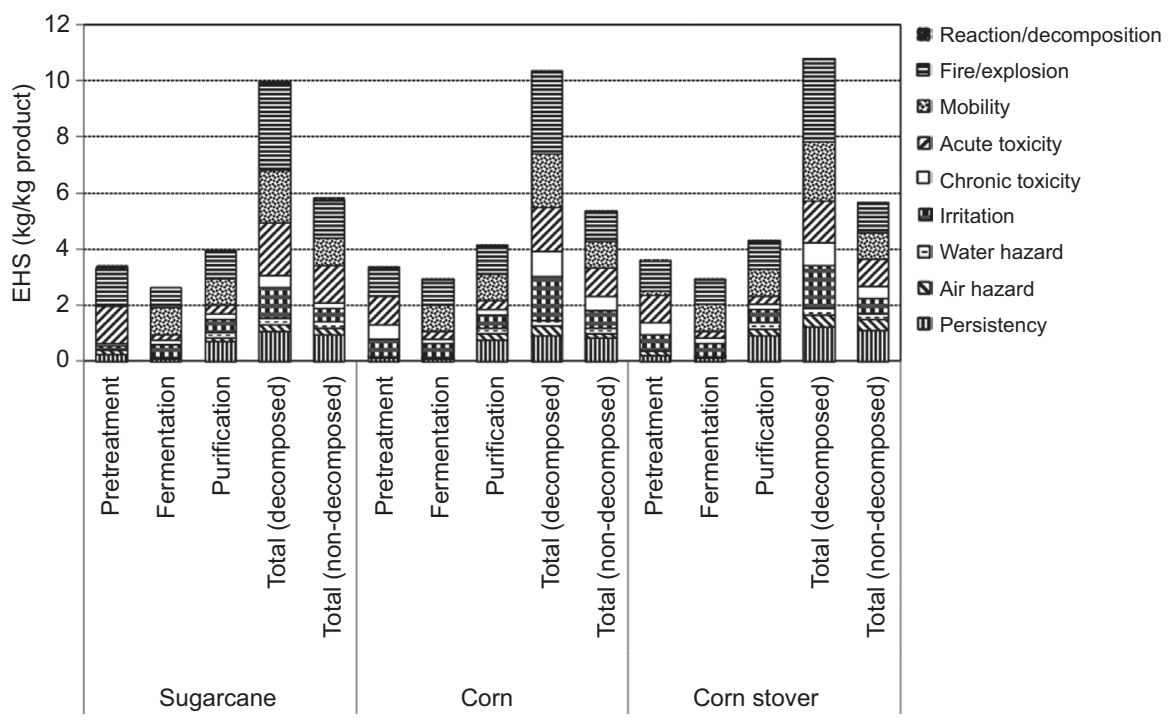

Figure 3 EHS hazard metric of alternative bioethanol production processes.

Hazardous substances used in high mass inventories (i.e., mass flows) result in higher EHS values. The process assessment is done in two ways: (i) by considering three different process sections separately (pretreatment, fermentation, and purification sections) resulting in the total (decomposed) endpoint score and (ii) by considering the whole process as one section resulting in the total (nondecomposed) endpoint score.

method (see also Table A1 in the Appendix), do not play a major role in the evaluation. Others, such as the mobility category referring to substance vapor pressures, are considered in the holistic categories of process temperature and pressure in the ISI method, therefore not being substance specific. The mobility category of the EHS method is important for the score of both the fermentation and the purification sections compared with the pretreatment section mainly due to $\mathrm{CO}_{2}$ produced during the fermentation.

Some other aspects of the EHS method, also responsible for the process section rankings, are the acute toxicity and fire/explosion categories, which are also considered by the ISI method in the category hazardous substance. These aspects severely penalize the pretreatment section of all production processes for the EHS method, whereas the differentiation effect for the ISI method is minimal. One reason for this lies in the fact that the EHS method is strongly influenced by the mass inventories of the considered substances, in this case of feedstock composition, which are multiplied with the substance intrinsic dangerous properties to quantify the respective hazards. On the other hand, the inventory category of the ISI method, which has some analogy to the mass of substances in the EHS method, is considered as a separate category without any multiplication effect. Moreover, as it is clear from Figure 2, the inventory category of the ISI method has a minor effect on the inferred rankings of the process sections for all feedstocks of the present study.

The potential for an agreement between the results of the ISI and the EHS methods is further investigated by assigning weights in the categories of the EHS method. The weights are let free to be optimized in various subranges between 0 and 1 , the only other constraint being that they have to sum up to 1 . The optimization goal is to maximize the Pearson's correlation coefficient (R-Pearson) between the two methods for the assessment of the decomposed bioethanol production processes based on the three different feedstocks. To this end, two different modes of the EHS method are used. In the first mode, the categories persistency, water and air hazards, irritation, and chronic toxicity are discarded (i.e., their weight was set to zero), because, according to Table A1 in the Appendix, only the categories acute toxicity, mobility, fire/explosion, and reaction/decomposition are commonly shared between the ISI and the EHS methods. In the second mode, all the categories of the EHS method are included. Figure 4A and $B$ depicts the respective results of these two modes, that is, the weights resulting in the maximum correlations and the respective correlation coefficient values. In the first mode (Figure 4A), it is clear that a significant agreement between the ISI and the EHS methods is achieved (i.e., with R-Pearson $>0.9$ ), when the categories of reaction/ decomposition and mobility obtain higher weights. This is also true in the second mode (Figure 4B), adding the 

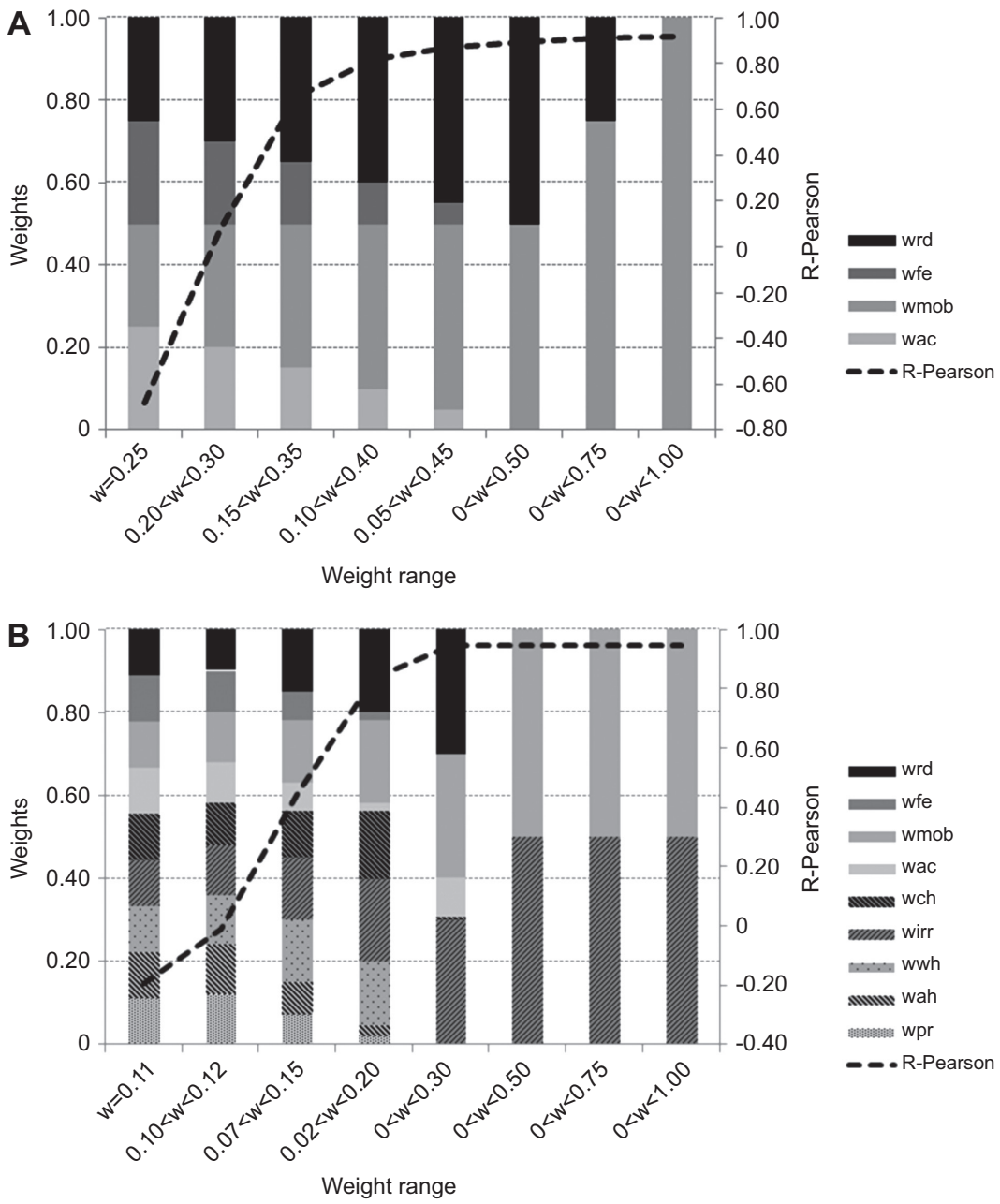

Figure 4 Agreement between the ISI and the EHS methods according to Pearson's correlation coefficient (R-Pearson) for the assessment results of the decomposed bioethanol production processes based on the three different feedstocks.

(A) First mode considering weights only for the categories reaction/decomposition (wrd), fire/explosion (wfe), mobility (wmob), and acute toxicity (wac) of the EHS method. (B) Second mode considering weights for all the categories of the EHS method, that is, also for chronic toxicity (wch), irritation (wirr), water hazards (wwh), air hazards (wah), and persistency (wpr).

categories of acute toxicity and irritation. The importance of chemical reactivity has been already mentioned during the analysis of the results of the ISI method (Figure 2) and the impact of mobility and acute toxicity has been already identified in the analysis of the EHS results (Figure 3). However, the effect of the irritation category was difficult to foresee based on the results of Figure 3. The main effect seems to be that, by assigning a higher weight to this category, which plays a minor role in the pretreatment section, the hazard value of this section decreases, resembling more the ISI assessment (Figure 2). Of course, it should be noted that these results are case specific and more elaborate and diverse case studies have to be conducted for inferring an optimal weighting for maximal agreement between the ISI and the EHS methods.
Despite the differences of the EHS and the ISI methods for the process section evaluation, the overall process ranking is the same, that is, the sugarcane-derived process is the least hazardous and the corn stover-derived process is the most hazardous. However, the EHS method appears to be more sensitive to the various boundary conditions of the analysis. In particular, when the whole process is considered as one section, the ranking is distorted in a greater effect compared with the ISI method, that is, the ranking of the sugarcane-derived process is completely changed from least to most hazardous. Here, it should be noted that the resolution of the endpoint indices for both the ISI and the EHS methods is not straightforward to infer, this aspect being currently a point of discussion for all hazard identification index-based methods $[38,39]$. 
Finally, like for the ISI method, a sensitivity analysis with respect to process conditions and feedstock biomass has also been performed for the EHS method. Although the impact on the EHS scores was more evident, it was still not significant enough to cause overall process ranking changes (see also section 3, Table S12 in the Supporting Information).

\subsection{Hazard vs. environmental impact}

For a multicriteria assessment of the bioethanol production processes, more than one aspect should be typically considered. In this study, a bicriteria profile with respect to hazard identification, expressed by the EHS and the ISI methods, and CED is presented in Figure 5. CED has been shown to have strong correlation with other LCIA metrics estimating the environmental burden [26-28]. In this study, cradle-to-gate CED values were estimated using the Ecoinvent database 2010 [40] and literature sources (see also section 4, Table S13 in the Supporting Information). It should be noted that several articles with a lifecycle orientation have already been published regarding the environmental performance of bio-based products. Especially in the case of corn, wide variations can be observed in the net energy value due to different agricultural production data, yields, ethanol conversion technologies, fertilizer manufacturing efficiency, fertilizer application rates, byproduct evaluation, and the number of energy inputs. Besides data sets, methodological issues, including choices of the system boundaries and allocation procedures, also can play a role for these variations [41]. Clearly, the sugarcane-derived process is significantly superior to the rest of the processes regarding both metrics followed by the corn-derived and the corn stover-derived processes. However, a tradeoff may also exist between the corn-derived and the corn stoverderived processes due to the overlapping regarding the ranges of the CED values. Whereas only material and energy input/output per functional unit is considered by LCIA (e.g., CED), hazard identification methods can express both extensive and intensive process parameters, such as process temperatures and pressures. However, it should be noted that the LCIA results involve a cradleto-gate analysis extending the system boundaries to include biomass production, byproduct recovery, and waste treatment of process effluents, whereas the hazard assessment refers to the local system of bioethanol production, whose boundaries are defined by the flowsheets in Figure 1A-C.

Generally, the same type of multicriteria analysis presented here based on the simplified flowsheets can be repeated with more detailed process information. In such a case, it is expected that the ISI method will be mainly affected by additional substances in the form of chemical auxiliaries that may have been neglected here, whereas the EHS method will be additionally more sensitive to updated mass flow values. As far as LCIA is concerned,

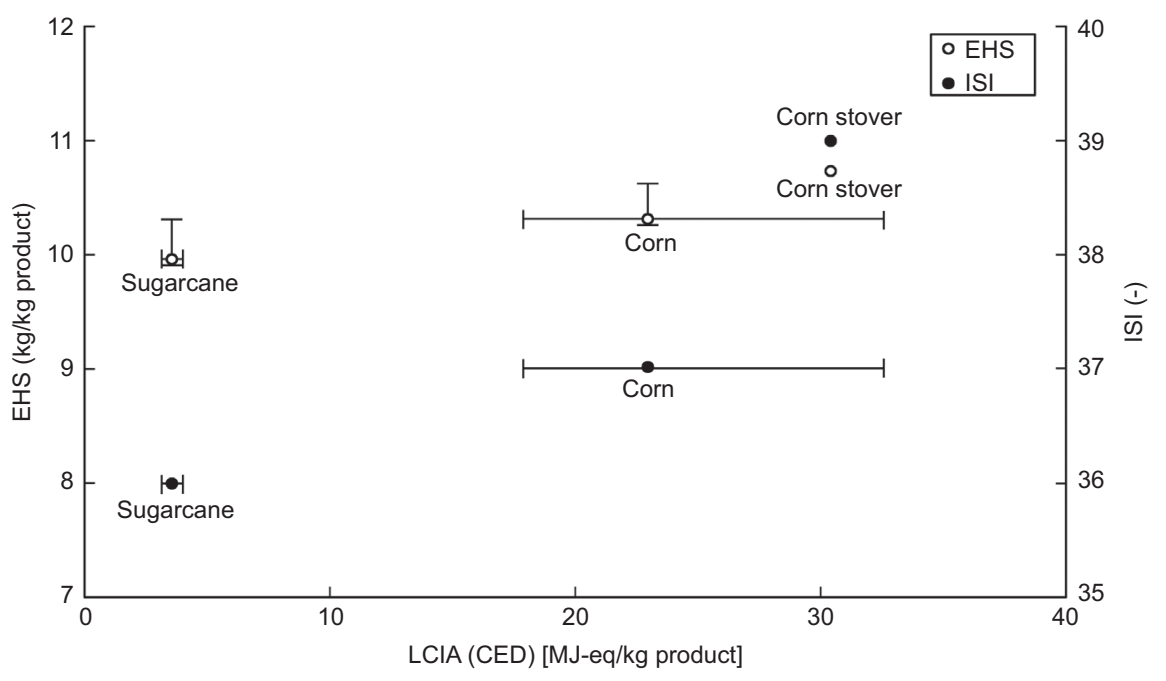

Figure 5 Hazard (EHS and ISI) vs. LCIA depicted by CED [LCIA (CED)].

The EHS and the ISI results refer to the base case analysis considering the different process sections, whereas the CED values are collected from various literature sources as expressed by the respective error bars (the exact values are reported in the Supporting Information). The error bars for the EHS method show the impact of different feedstock composition and process conditions, whereas the ISI scores are not affected (CED for conventional ethanol: $48 \mathrm{MJ}$-eq/kg product [40]). 
more detailed flowsheets could provide incentives for energy and mass integration approaches, therefore updating the calculation of gate-to-gate emissions, water, and energy consumption $[42,43]$.

\subsection{Green bioethanol process design}

Green process design for bioethanol production should consider safety, health, and environmental hazards as well as lifecycle impacts [17]. The three types of bioethanol production in this study, that is, ethanol derived from sugarcane, corn, and corn stover, refer to the most representative biomass resources for sucrose-containing materials, starch materials, and lignocellulosic biomass. Therefore, based on the results of this study, a new viewpoint, that is, process hazard assessment, can be implemented into bioethanol production in addition to economic aspects, LCIA, resource availability, and use of land and water discussed by other researchers [14-16]. In this context, the specific category of environmental impacts related with nutrients used in biomass cultivation, such as nitrogen, phosphorus, and potassium, is also important and their input/output balances and cycles among involved carriers such as animal and plant should be carefully considered [44]. However, this detailed analysis lies outside the scope of the present study, which mainly focuses on the hazard assessment of biomass technologies as one of the additional elements for sustainable bioethanol production.

The second-generation bioethanol technologies based on lignocellulosic biomass have been developed due to non-competition with food supplies. This study considered only corn stover from this category and demonstrated that the hazards of the respective process are higher, whereas its CED value might be lower than that of the corn-based process. This higher hazard is due to the pretreatment section as indicated by both the ISI and the EHS methods, pointing out to the necessity for further development of technologies for the pretreatment of corn stover considering safety, health, and environmental perspectives. A review of different pretreatment options can be found in scientific literature $[1,45]$. From the ISI point of view, it would be beneficial to target at milder process conditions (i.e., lower temperatures and pressures), because this was the main reason for penalizing the corn stover pretreatment section. To this end, the technologies of ammonia fiber explosion (AFEX) and liquid hot water (LHW) could be considered. On the one hand, similar process pressure and milder process temperature are reported for AFEX $\left(\sim 90^{\circ} \mathrm{C}\right)$, but a system for ammonia recovery is required that complicates the process and may further penalize it from the EHS point of view. On the other hand, the LHW process is simpler, which becomes more relevant for the ISI method, if the subindices for equipment safety and process structure are considered in the calculation. However, the LHW process does not involve lower temperatures $\left(170-230^{\circ} \mathrm{C}\right)$ or pressures $(>5 \mathrm{MPa})$. The impact of these other pretreatment options according to the EHS method is more difficult to foresee because a mass balance is required. However, these methods have not been yet implemented in large scales, and the respective process data are not of the same accuracy. This is also true for other reported pretreatment options (e.g., involving supercritical fluids or irradiation). For this reason, these pretreatment options are not included in the current study but certainly constitute material for future research. Moreover, similar studies for other lignocellulosic biomass resources (e.g., switch grass) are necessary to provide a more complete evaluation profile of the second-generation bioethanol technologies, which are constantly gaining interest. It would also be interesting to compare the bioethanol production routes described here with conventional ethanol production methods to highlight the advantages as well as the challenges.

Finally, as mentioned above, the ISI and the EHS methods do not share a common analysis scope and can reveal different aspects of process hazards. From the process safety viewpoint of the ISI method, the highest hazard is allocated in the fermentation process of all biomass technologies, whereas the EHS method highlights the purification section as the most hazardous. Therefore, this study shows that it is important not only to consider hazard assessment methods for a multicriteria process design but also to comprehend the different basis and scope of such methods.

\section{Appendix}

This table lists the basic settings of the ISI and the EHS methods in terms of process conditions, impact categories, and property data taken into account. It is intended to demonstrate similarities and differences about the considered aspects in process assessment, whereas detailed information about the calculations schemes (i.e., including scaling of individual categories and aggregation procedures) can be found in original literature $[22,37]$. 


\begin{tabular}{|c|c|c|c|}
\hline Aspect & Dangerous properties & ISI & EHS \\
\hline \multirow[t]{5}{*}{ Process } & Inventory & Total mass & Mass flow \\
\hline & Temperature & $\mathrm{T}_{\max }$ & $\mathrm{T}_{\text {process }}$ \\
\hline & Pressure & & $P_{\text {process }}^{\text {process }}$ \\
\hline & Equipment safety & Equipment type/layout & - \\
\hline & Process structure & Kind of operations & - \\
\hline \multirow[t]{8}{*}{$\underline{\text { Safety }}$} & Reaction hazards & Enthalpy released & - \\
\hline & Chemical interaction & EPA's matrix & - \\
\hline & Fire & $\mathrm{Fp}$ & $\triangle \mathrm{Fp}, \mathrm{NFPA}$ \\
\hline & Explosion & LEL, UEL & $\triangle \mathrm{Fp}, \mathrm{NFPA}$ \\
\hline & Toxicity & TLV & IDLH/GK/R-codes \\
\hline & Mobility & - & $\mathrm{pi}^{\circ} / \Delta \mathrm{Bp}$ \\
\hline & Reaction/decomposition & - & NFPA/R-codes \\
\hline & Corrosiveness & Type of chemicals & - \\
\hline \multirow[t]{2}{*}{ Health } & & - & LD50 $0_{\text {dermal }} /$ R-codes \\
\hline & & - & MAK/GK/R-codes \\
\hline \multirow[t]{3}{*}{ Environmental } & & - & Half-life $_{\text {water }}$ \\
\hline & & - & R-codes \\
\hline & & - & LC50 ${ }_{\text {aquatic }} / \mathrm{R}$-codes/WGK \\
\hline
\end{tabular}

Table A1 Basic settings of the ISI and the EHS methods.

Fp, flash point; $\mathrm{pi}^{\circ}$, vapor pressure; Bp, boiling point; LEL, lower explosion limit; IDLH, immediately dangerous to life and health; NFPA, National Fire Protection Association; UEL, upper explosion limit; LD50 ${ }_{\text {dermal }}$, lethal dose via dermal exposure (rat, mouse, and rabbit); GK, Swiss poison class; TLV, threshold limit value; $\mathrm{LC5}_{\text {aquatic }}$, aquatic lethal concentration (Daphnia magna); WGK, German water hazard class.

\section{Supporting information available}

The supporting information consists of five sections providing (1) feed composition data for the considered biomass resources, (2) reaction and mass balance assumptions and calculations, (3) sensitivity analysis scenarios,
(4) CED data from various literature sources, and (5) the relevant references.

Supplementary Material to this article can be obtained at http://www.degruyter.com/view/j/gps

Received June 4, 2012; accepted September 2, 2012; previously published online October 5, 2012

\section{References}

[1] Sánchez J, Cardona CA. Bioresour. Technol. 2008, 99, 5270-5295.

[2] Cardona CA, Sánchez J. Bioresour. Technol. 2007, 98, 2415-2457.

[3] Moiser N, Wyman C, Dale B, Elander R, Lee YY, Holtzapple M, Ladisch M. Bioresour. Technol. 2005, 96, 673-686.

[4] Hamelinck CN, Hooijdonk GV, Faaij APC. Biomass Bioenergy 2005, 28, 384-410.

[5] Hamelinck CN, Suurs RAA, Faaij APC. Biomass Bioenergy 2005, 29, 114-134.

[6] Pimentel D. Nat. Resour. Res. 2003, 12, 127-134.

[7] Pimentel D, Patzek WT. Nat. Resour. Res. 2005, 14, 65-75.

[8] Liska AJ, Yang HS, Bremer VR, Klopfenstein TJ, Walters DT, Erickson GE, Cassman KG. J. Ind. Ecol. 2009, 13, 58-74.

[9] Plevin RJ. J. Ind. Ecol. 2009, 13, 495-507.

[10] Macedo IC, Seabra JEA, Silva JEAR. Biomass Bioenergy 2008, 32, 582-595.

[11] Luo L, Van der Voet E, Huppes G. Renew. Sust. Energ. Rev. 2009, 13, 1613-1619.
[12] Sheehan J, Aden A, Paustian K, Killian K, Brenner J, Walsh M, Nelson R. J. Ind. Ecol. 2003, 7, 117-146.

[13] Luo L, Van der Voet E, Huppes G. Renew. Sust. Energ. Rev. 2009, 13, 2003-2011.

[14] Hedegaard K, Thyø KA, Wenzel H. Environ. Sci. Technol. 2008, 42, 7992-7999.

[15] Gopalakrishnan G, Negri MC, Wang M, Wu M, Snyder SW, Lafreniere L. Environ. Sci. Technol. 2009, 43, 6094-6100.

[16] Cai X, Zhang X, Wang D. Environ. Sci. Technol. 2011, 45 , 334-339.

[17] Jiménez-González C, Constable DJC, Eds., Green Chemistry and Engineering: A Practical Design Approach, John Wiley \& Sons: New Jersey, 2011.

[18] Fukushima Y, Kikuchi Y, Kajikawa Y, Kubota M, Nakagaki T, Matsukata M, Kato Y, Koyama M. J. Chem. Eng. Jpn. 2011, 44, 365-369.

[19] Li X, Zanwar A, Jayswal A, Lou HH, Huang Y. Ind. Eng. Chem. Res. 2011, 50, 2981-2993. 
[20] Brandes E, Frobese DH. Forsch. Ing.wes.-Eng. Res. 2009, 73, 25-32.

[21] Nguyen THT, Kikuchi Y, Noda M, Sugiyama H, Hirao M. Proc. 20th ESCAPE, Comput. Aided Chem. Eng. 2010, 27, 1955-1960.

[22] Heikkilä A. Inherent Safety in Process Plant Design, VTT Publications 384. Technical Research Center of Finland: Espoo, Finland, 1999.

[23] Koller G, Fischer U, Hungerbühler K. Ind. Eng. Chem. Res. 2000, 39, 960-972.

[24] Carvalho A, Gani R, Matos H. Process. Saf. Environ. 2008, 86, 328-346.

[25] Sugiyama H, Fischer U, Hungerbühler K, Hirao M. AlChE J. 2008, 54, 1037-1053.

[26] Wernet G, Mutel C, Hellweg S, Hungerbühler K. J. Ind. Ecol. 2011, 15, 96-107.

[27] Huijbregts MAJ, Rombouts LJA, Hellweg S, Frischknecht R, Hendriks AJ, Van de Meent D, Ragas AMJ, Reijnders L, Struijs J. Environ. Sci. Technol. 2006, 40, 641-648.

[28] Huijbregts MAJ, Hellweg S, Frischknecht R, Hendriks HWM, Hungerbühler K, Hendriks AJ. Environ. Sci. Technol. 2010, 44, 2189-2196.

[29] Quintero JA, Montoya MA, Sánchez OJ, Giraldo OH, Cardona CA. Energy 2008, 33, 385-399.

[30] Rein P. Cane Sugar Engineering, Verlag Dr. Albert Bartens KG: Berlin, 2007.

[31] McAloon A, Taylor F, Yee W, Ibsen K, Wooley R. Determining the Cost of Producing Ethanol From Corn Starch and Lignocellulosic Feedstocks, National Renewable Energy Laboratory: Golden, CO, Report No. NREL/TP-580-28893, 2000. Available at: http://www.agmrc.org/media/cms/16_5299EA3DD888C.pdf.

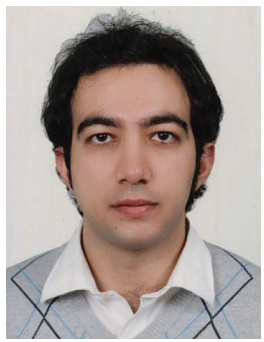

Alireza Banimostafa is a PhD student at the Institute for Chemical- and Bioengineering, ETHZ, Switzerland. He holds a bachelor's degree in chemical engineering from Tehran Polytechnic, Iran, and a master's degree in Industrial Engineering and Management from Chalmers University of Technology, Sweden. His current research focuses on multicriteria process design and optimization, including green engineering $(\mathrm{EHS} / \mathrm{LCIA})$ principles.
[32] Taylor F, Marquez AM, Johnston BD, Goldberg MN, Hicks BK. Bioresour. Technol. 2010, 101, 4403-4408.

[33] Kwiatkowski JR, McAloon AJ, Taylor F, Johnston DB. Ind. Crop. Prod. 2006, 23, 288-296.

[34] Wooley R, Ruth M, Sheehan J, Ibsen K, Majdeski H, Galvez A. Lignocellulosic Biomass to Ethanol Process Design and Economics Utilizing Co-current Dilute Acid Prehydrolysis and Enzymatic Hydrolysis Current and Futuristic Scenarios, National Renewable Energy Laboratory: Golden, CO, Report No. NREL/ TP-580-26157, 1999. Available at: http://www.nrel.gov/docs/ fy990sti/26157.pdf.

[35] Rahman M, Heikkila AM, Hurme M. J. Loss Prevent. Proc. 2005, 18, 327-334.

[36] Adu IK, Sugiyama H, Fischer U, Hungerbühler K. Process Saf. Environ. Prot. 2008, 86, 77-93.

[37] Banimostafa A, Papadokonstantakis S, Hungerbühler K. Process Saf. Environ. Prot. 2012, 1, 8-26.

[38] Gentile M, Rogers WJ, Mannan MS. Process Saf. Environ. Prot. 2003, 81, 444-456.

[39] Srinivasan R, Nhan NT. Process Saf. Environ. Prot. 2008, 86, 163-174.

[40] Ecoinvent data v2.2, Ecoinvent Centre, 2010. Swiss Center for Life Cycle Inventories.

[41] Kim S, Dale BE. J. Ind. Ecol. 2003, 7, 147-162.

[42] Karuppiah R, Peschel A, Grossmann IE. AIChE J. 2008, 54, 1494-1525.

[43] Martin M, Ahmetovic E, Grossmann IE. Ind. Eng. Chem. Res. 2011, 50, 3705-3721.

[44] Spiess E. Nutr. Cycl. Agroecosys. 2011, 91, 351-365.

[45] Lynd LR. Annu. Rev. Energy Environ. 1996, 21, 403-465.

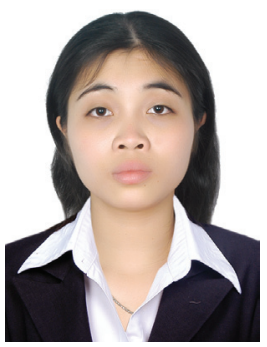

Dr. Thuy Thi Hong Nguyen is a researcher at the Department of Chemical System Engineering, The University of Tokyo, Japan. She holds a master's degree and PhD in chemical system engineering from The University of Tokyo, Japan. Her research focuses on modeling reaction kinetics, developing new processes for chemical and energy producing plants, modeling and optimization of novel chemical processes, process safety and environmental protection, raw material management, and supply chain sustainability. 


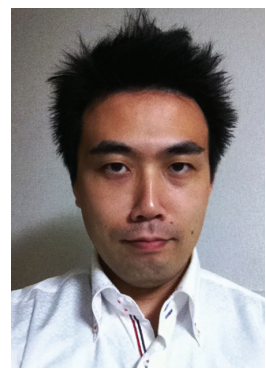

Dr. Yasunori Kikuchi is a project lecturer of Presidential Endowed Chair for "Platinum Society" and the Department of Chemical System Engineering, The University of Tokyo, Japan. He specializes in process systems engineering, lifecycle engineering, and industrial ecology.

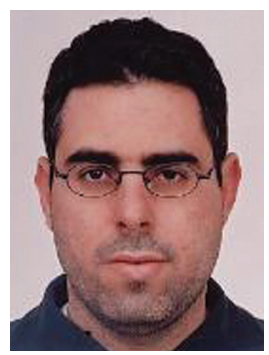

Dr. Stavros Papadokonstantakis is a senior research associate and lecturer at the Institute for Chemical- and Bioengineering, ETHZ, Switzerland. He holds a master's degree and a PhD in chemical engineering from the National Technical University of Athens, Greece. Before joining the ETHZ in 2006, he has worked as a chemical engineering consultant (American Process, Inc., Atlanta, $\mathrm{GA}$ ) in the field of modeling chemical processes using data mining. He leads the chemical process design and optimization subdivision of the Safety and Environmental Technology Group in ETHZ. His research focuses on the methods for designing and optimizing chemical processes considering multiple objectives, with focus on early stages of process design, flowsheet decomposition techniques, lifecycle analysis, and safety, health, and environmental hazard assessment.

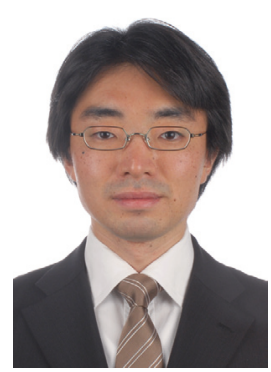

Dr. Hirokazu Sugiyama is a part-time lecturer at the Institute for Chemical- and Bioengineering, ETHZ, Switzerland. He studied chemical engineering at the University of Tokyo and earned his PhD from ETH Zurich, with a thesis on decision-making framework for chemical process design considering the EHS aspects.

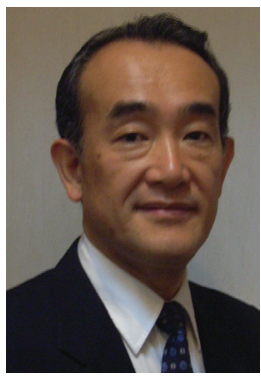

Prof. Dr. Masahiko Hirao is a professor at the Department of Chemical System Engineering, The University of Tokyo, Japan. His current research interests are in the topics of sustainable chemical process design and sustainable social system design, such as recycling systems based on lifecycle assessment.

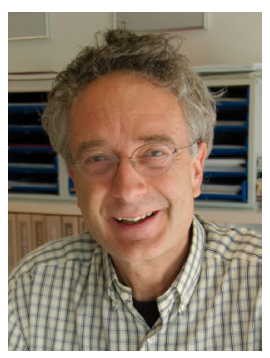

Prof. Dr. Konrad Hungerbühler is a professor at the Institute for Chemical- and Bioengineering, ETHZ, Switzerland. He leads the Safety and Environmental Technology Group, dealing with the integrated development of chemical processes and products. His extensive industrial experience as the Head of the Process Development and Research and Development in Ciba-Geigy (Switzerland) and his academic research have resulted in substantial expertise in the topics of process systems engineering and multicriteria process assessment and optimization, including technical, economic, and environmental performance as well as the degree of (inherent) process safety. He is the author of more than 260 publications in peer-reviewed scientific journals and one monograph in the field of risk assessment. 